\title{
Prediction of Nominal Compressive Strength in Steel Piles Subject to Corrosion Losses: A Finite Element Approach
}

\author{
Breanna Bailey, Sidiq A. Osomo \\ Texas A\&M University-Kingsville, MSC 194700 University Blvd, Kingsville, TX 78363, USA \\ E-mail: breanna.bailey@tamuk.edu
}

Received: 30 July 2019; Accepted: 30 August 2019; Available online: 20 November 2019

\begin{abstract}
This paper presents a method for predicting the nominal compressive strength of steel I-shaped piles subject to cross-sectional losses caused by corrosion. The method requires a finite element linear buckling analysis of the corroded cross-section. Results from the finite element buckling analysis may be integrated into design capacity equations contained in the 15th edition of the American Institute of Steel Construction Steel Construction Manual. Non-linear post-buckling analyses were used to verify the accuracy of the proposed method. Three crosssectional geometries (W14x82, W14x90, and W14x120) were analyzed at varying degrees of cross-sectional loss. Results show close agreement between the non-linear finite element analyses and the proposed method of calculating nominal compressive strength.
\end{abstract}

Keywords: Corrosion; Finite element; Compressive strength.

\section{Introduction}

This paper presents a method (the $\mathrm{F}_{\text {e(buckle) }}$ method) for predicting the nominal compressive strength of steel Ishaped piles subject to cross-sectional losses caused by corrosion. Linear and non-linear final element studies of three I-shaped cross-sections were reconciled with design capacities using the 15th edition of the American Institute of Steel Construction Steel Construction Manual (AISC manual) [1].

\subsection{Motivation}

Corrosion is a well-documented phenomenon that occurs when steel reacts with water and air to form iron oxides [2]. In the case of exposed steel structures in coastal or marine environments, corrosion is likely to lead to a gradual degradation of structural components. Corrosion can be concentrated locally to form a pit or crack, or it can extend across a wide area on the surface. Because corrosion is a diffusion-controlled process, it occurs on exposed surfaces. As a result, methods to reduce activity on the exposed surface, such as passivation and chromate conversion, can increase a material's corrosion resistance [3]. Despite efforts to reduce corrosion, however, exposed structural steel members in coastal or marine environments will experience a gradual loss in the crosssection of structural components. This loss in cross-section correlates to reduced structural capacity [4]. The adverse effects of corrosion on coastal structures, as well as associated economic impacts, are well established [5, $6]$.

This study investigates the post-buckling strength of different structural steel I-shaped members assumed to act as piles (compressive members) in a marine environment. The goal of the study was to form a predictive model that could be used to determine residual capacity in a corroded compression member. Results from finite element studies were compared to equations in Ch. E of the AISC manual, with the ultimate goal of creating a model for predicting capacity as a function of corrosion loss. This paper contains information for an intermediate prediction method.

\subsection{Literature review}

The following is a brief summary of related research. Researchers in [7] investigated the elastic buckling of steel columns in axial compression for square, rectangle, and circular cross sections with varying boundary conditions. Results showed that finite element and Euler equation results for critical loads agreed within $0.01 \%$ to $0.29 \%$ [7]. This work verifies the reliability of finite element studies in predicting critical buckling loads for columns.

In another finite element study, researchers conducted non-linear and post-buckling analyses of a cylindrical shell [8]. Results of the limit point load from the classical formula and that obtained from the eigenvalue extraction of the linear analysis were in agreement. The study adopted the first mode shape as the initial geometrical 
imperfection and performed both non-linear and post-buckling analysis. It was observed that the magnitude and mode shape of initial imperfection plays a predominant role in evaluating the variation of limit point load for an imperfect cylindrical shell [8]. The post-buckling analyses performed in the current work likewise use the first mode shape from an eigenvalue analysis to create initial imperfections.

With a focus on predicting the degree of corrosion likely to occur, [9] studied the behavior of deteriorating steel structures exposed to atmospheric conditions. Researched used a probabilistic analysis due to limited availability of corrosion data and challenges modeling dependencies between variables affecting corrosion rates. Consequently, it was concluded that the probabilistic approach was the best methodology for estimating corrosion rates [9]; this research did not attempt to estimate the effect of corrosion rate on steel strength.

Similarly, [4] investigated the gradual depletion of steel structures in a marine environment to find indicative values for the corrosion rate of steel sheet piles. Researchers estimated cross-sectional losses of the steel sheet piles over a period of 36 to 51 years. The measured average corrosion rates were the same as those used in the European code. However, they discovered increased corrosion rates at 3.28 in below the mean water surface and at the level of propellers from berthing ships in the most frequented of the inspected wharfs (ie, in the splash zone) [4]. The concept of increased corrosion in the splash zone is modeled in the current study as well.

Initial attempts by the author and associates to estimate residual compressive capacity as a function of crosssection loss are summarized in [10]. This work presents elastic critical buckling loads of different pile cross sections with corrosion losses in the splash zone. Using linear finite element buckling analysis, it was discovered that after the rectangular and hollow sections were subjected to $75 \%$ section losses, they still retained more than $70 \%$ of their capacity. However, the I-shaped section became unstable for material losses exceeding $25 \%$ of cross section because the loss of flange width significantly reduced the moment of inertia. The present research expands these initial studies by providing non-linear, post-buckling analyses for I-shaped cross-sections.

\section{Methodology}

\subsection{Model details}

Twelve finite element models were analyzed as part of this study. These twelve models represented three wideflange beam geometries (W14x82, W14x90, and W14x120) with varying degrees of cross-section reductions to model corrosion loss. This study focused on W14s of similar size in order to reduce, but not entirely eliminate, behavior variations related to size. The basic model geometry is illustrated in Figure 1. All models were 30 feet long with a fixed support at one end to model a pile driven into the mudline. The top of the piles were modeled as free to translate but not rotate. The splash zone was modeled to be 5 feet in length and to occur 10 feet from the top of the pile and 15 feet from the fixed pile foundation. These conditions were based on observed pile behavior in an existing pier.

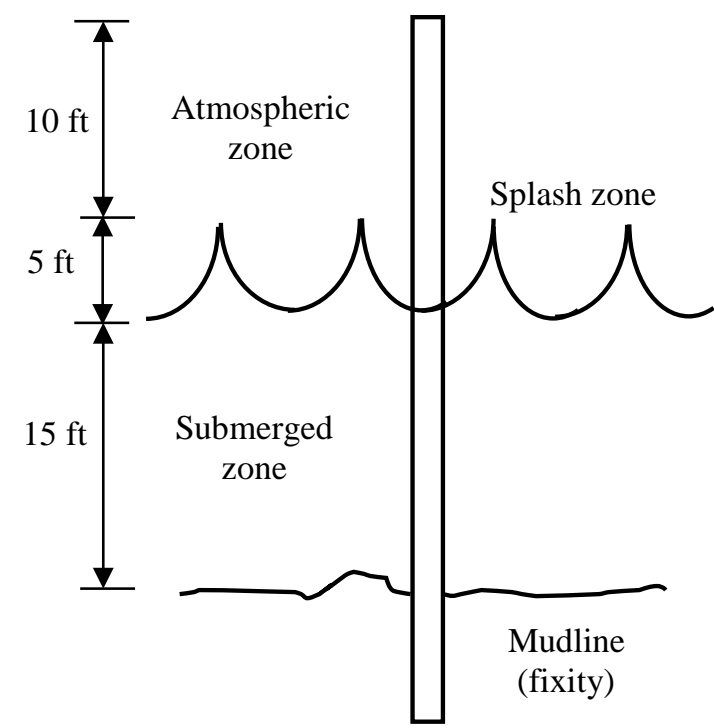

Figure 1. Schematic illustration of basic model geometry and boundary conditions.

The splash zone is defined as the region immediately above and below the mean water level. Tides cause the water level to rise and fall, thereby intermittently exposing the spile to the atmosphere. The alternate wetting and drying causes a higher rate of corrosion than elsewhere along the column length. Some level of protection can be provided for the submerged zone by cathodic means but not in the splash zone. 
To model corrosion loss in the splash zone, the width of the column flanges was reduced. Width reduction was selected to model observed behavior in the field. Flanges were eroded from the edges inward to represent a total loss of $25 \%, 50 \%$, and $75 \%$ of the original un-corroded cross-sectional area. The W14 piles were also modeled in their non-corroded state (i.e., $0 \%$ section loss). Table 1 summarizes the cross-sectional areas for all twelve models of this research study. Cross-sectional properties for the corroded models were calculated based on the reduced (corroded) cross-section in the splash zone.

Table 1. Cross-sectional areas for finite element models

\begin{tabular}{lllll}
\hline Model Geometry & $\begin{array}{l}\text { 0\% Section Loss } \\
\left.\text { Area (in }{ }^{2}\right)\end{array}$ & $\begin{array}{l}\text { 25\% Section Loss } \\
\text { Area }\left(\mathbf{i n}^{2}\right)\end{array}$ & $\begin{array}{l}\text { 50\% Section Loss } \\
\text { Area }\left(\mathbf{i n}^{2}\right)\end{array}$ & $\begin{array}{l}\text { 75\% Section Loss } \\
\text { Area }\left(\mathbf{i n}^{2}\right)\end{array}$ \\
\hline W14x82 & 24.1 & 20.29 & 15.96 & 11.63 \\
W14x90 & 26.5 & 21.63 & 16.48 & 11.32 \\
W14x120 & 35.3 & 29.22 & 22.33 & 15.44 \\
\hline
\end{tabular}

\subsection{Finite element analyses}

ABAQUS finite element software was used for the analysis of the twelve W14 models in this study. Each model was analyzed twice. First, a linear buckling analysis was performed to determine the critical buckling load for the piles as well as the first buckled mode shape. Second, a non-linear post-buckling analysis was conducted using the modified Riks method available in ABAQUS. The first buckled mode shape from the linear analysis was used to create an initial geometric imperfection in the Riks analysis.

Conventional shell elements were used to create the finite element models. Conventional shell elements were selected because they allow for displacement and rotational degrees of freedom, while the continuum shell elements allow for displacement degrees of freedom only. Element type S4R was used, which is a four-node quadrilateral, stress/displacement conventional shell element with reduced integration and a large-strain formulation. S4R elements use thick shell theory as the shell thickness increases and become discrete Kirchhoff thin shell elements as the thickness decreases [11]. All models in this study used a modulus of elasticity of 29,000 ksi and a Poisson's ratio of 0.3 .

The linear perturbation (buckling analysis) used the subspace eigenvalue extraction method available in ABAQUS because this solver is faster when only a few mode shapes are required [11]. Load and boundary conditions were applied on the top and bottom node sets via a reference point using rigid body tie (node) constraints. Rigid body tie constraints simplified the application of the boundary condition and load on the model; experimentation revealed that these constraints also gave closer results to theoretical values for non-corroded models.

An initial concentrated load of $1 \mathrm{lb}$. was centered at the free end of the model. The eigenvalue is extracted from the buckling analysis and used to estimate the critical bifurcation load. The bifurcation load is the load at which the model stiffness matrix is singular [11]. For non-corroded members, the bifurcation load (or critical load, $\mathrm{P}_{\mathrm{cr}}$ ) should correspond to the theoretical Euler buckling load of Equation (1). In Equation 1, E represents the modulus of elasticity, I the moment of inertia, $\mathrm{L}$ the length of the compression member, and $\mathrm{K}$ the effective length factor. For the geometry of the present study, the value of $\mathrm{K}$ is theoretically 1 [1].

$$
P_{c r}=\frac{\pi^{2} E I}{(K L)^{2}}
$$

The post-buckling Riks analysis considered both geometric and material nonlinearity. To introduce material nonlinearity, the models included a yield strength of $50 \mathrm{ksi}$, ultimate strength of $80 \mathrm{ksi}$, and a plastic strain of $0.15 \%$ (corresponds to American Iron and Steel Institute 1020 steel). The extracted mode shape from the linear buckling analysis was used to create an initial imperfection to serve as the source of geometric nonlinearity in the Riks analysis.

The critical buckling load obtained from the linear buckling analysis is applied as load in the Riks analysis. Output from the Riks analysis includes a plot of the load proportionality factor (LPF) vs. arc length. This plot is used to identify a peak LPF value ( $\lambda$ ). Equation (2) may be used to estimate the compressive capacity of the pile member at failure $\left(\mathrm{P}_{\mathrm{n}}\right)$. To distinguish results obtained from finite element analysis (FEA) from results obtained from theoretical or AISC equations, the variable $\mathrm{P}_{\mathrm{n} \text { (post) }}$ will refer to values obtained from Riks analysis and $\mathrm{P}_{\text {cr(buckle) }}$ will refer to values obtained from the buckling analysis.

$$
P_{n(\text { post })}=\lambda * P_{\text {cr }(\text { buckle })}
$$

\subsection{Integration with AISC calculations}

In Section E3, the AISC manual calculates the compressive capacity of flexural buckling members without 
slender elements as a function of the critical stress $\left(\mathrm{F}_{\mathrm{cr}}\right)$ and the gross area $\left(\mathrm{A}_{\mathrm{g}}\right)$ of the cross-section, as shown in Equation (3).

$$
P_{n}=F_{c r} A_{g}
$$

The value of $\mathrm{F}_{\mathrm{cr}}$ is a function of the slenderness of the column as expressed by the ratio of the effective length $\left(L_{c}\right.$, which is equal to KL) to the radius of gyration (r). Slender columns are more likely to fail elastically at a compressive strength similar to that calculated from Equation (1), whereas intermediate columns will exhibit inelastic buckling prior to reaching $\mathrm{P}_{\mathrm{cr}}$. To reconcile these two behaviors, the AISC code has two equations for $\mathrm{F}_{\mathrm{cr}}$. However, both definitions make use of the elastic buckling stress $\left(\mathrm{F}_{\mathrm{e}}\right)$, as expressed in Equation (4). Substituting the definition for the radius of gyration reveals that AISC's elastic buckling stress is identical to the stress at the Euler buckling load of Equation (1).

$$
F_{e}=\frac{\pi^{2} E}{\left(\frac{L_{c}}{r}\right)^{2}}=\frac{P_{c r}}{A_{g}}
$$

In the AISC code, the elastic buckling stress may be alternatively defined "through an elastic buckling analysis, as applicable” [1]. The hypothesis put forward in this paper is that $\mathrm{F}_{\mathrm{e}}$ of Equation (4) may be replaced by an elastic buckling stress $\left(\mathrm{F}_{\mathrm{e}(\text { buckle) }}\right)$ calculated from the results the linear perturbation buckling analysis performed in ABAQUS, as expressed in Equation (5). This definition for the elastic buckling stress can then be directly implemented into the remaining AISC Ch. 3 equations and used to calculate the nominal compressive capacity, Equation (3).

$$
F_{e(\text { buckle })}=\frac{P_{\text {cr(buckle })}}{A_{g}}
$$

As it currently stands, Equation (5) allows for only one definition of gross area for the column, despite the fact that the corroded finite element models experience section loss in the splash zone alone. The gross areas for the corroded models were assumed to be equal to the reduced cross-sectional area in the region of corrosion (ie, the splash zone).

\section{Results}

Table 2 compares the critical buckling loads extracted from the AQBAQUS linear buckling analysis with the Euler buckling loads calculated using Equation (1). These results are for the non-corroded cross-sections only. ABAQUS results agree with theoretical Euler buckling results within 1\%. This step was an important verification of the non-corroded models.

Table 2. Comparison of ABAQUS to theoretical critical buckling loads for non-corroded cross-sections

\begin{tabular}{llll}
\hline $\begin{array}{l}\text { Model Geometry } \\
\text { (0\% Corrosion) }\end{array}$ & $\begin{array}{l}\mathbf{P}_{\text {cr(buckle) }} \text { from ABAQUS } \\
\text { (kips) }\end{array}$ & $\left.\begin{array}{l}\mathbf{P}_{\text {cr from Euler Equation }} \text { (kips) } \\
\text { W14X82 }\end{array}\right) \begin{array}{l}\text { Difference } \\
\text { (\%) }\end{array}$ \\
W14x90 & 324 & 327 & 0.92 \\
W14x120 & 795 & 800 & 0.63 \\
\end{tabular}

Table 3 compares the results of the Riks post-buckling analysis, $\mathrm{P}_{\mathrm{n}(\mathrm{post})}$, to expected nominal compressive strength, $\mathrm{P}_{\mathrm{n}}$, calculated in accordance with AISC equations in section E3 for the non-corroded cross-sections. The ABAQUS results agreed with the AISC manual calculations within 6\%. Results from the ABAQUS post-buckling analysis are slightly higher than those obtained from theory, which is expected since finite element solutions tend to be stiffer than real systems. The overall agreement, however, is good, and justifies the use of finite element nonlinear, post-buckling analyses to estimate failure capacities for the piles.

Table 4 extends the results of Table 3 for the non-corroded cross-sections. In Table 4, the nominal compressive strengths, $\mathrm{P}_{\mathrm{n}}$, have both been calculated using Equation (3) in accordance with AISC provisions. However, the second column of Table 4 presents values of $\mathrm{P}_{\mathrm{n}}$ calculated using the proposed $\mathrm{F}_{\mathrm{e} \text { (buckle) }}$ of Equation (5), whereas the $P_{n}$ values of the third column come directly from AISC and Equation (4). This method bypasses the postbuckling analysis, which tends to be both more difficult and lengthy to conduct, and replaces it with a simpler linear buckling analysis. The proposed method agrees with AISC results with less than $1 \%$ of difference for the non-corroded models. 
Table 3. Comparison of ABAQUS and AISC compressive strengths for non-corroded cross-sections

\begin{tabular}{llll}
\hline $\begin{array}{l}\text { Model Geometry } \\
\text { (0\% Corrosion) }\end{array}$ & $\begin{array}{l}\mathbf{P}_{\text {n(post) }} \text { from ABAQUS } \\
\text { (kips) }\end{array}$ & $\begin{array}{l}\mathbf{P}_{\mathbf{n}} \text { from AISC using } \mathbf{F}_{\mathbf{e}} \\
\text { (kips) }\end{array}$ & $\begin{array}{l}\text { Difference } \\
\text { (\%) }\end{array}$ \\
\hline W14X82 & 293.5 & 286.2 & 2.56 \\
W14x90 & 693.2 & 662.5 & 4.63 \\
W14x120 & 945.0 & 896.0 & 5.47 \\
\hline
\end{tabular}

Table 4. Comparison of ABAQUS and AISC compressive strengths for non-corroded cross-sections using proposed method of estimating elastic buckling stress

\begin{tabular}{llll}
\hline $\begin{array}{l}\text { Model Geometry } \\
\text { (0\% Corrosion) }\end{array}$ & $\begin{array}{l}\mathbf{P}_{\mathbf{n}} \text { from AISC using F (buckle) } \\
\text { (kips) }\end{array}$ & $\begin{array}{l}\mathbf{P}_{\mathbf{n}} \text { from AISC using } \text { Fe }_{\mathbf{e}} \\
\text { (kips) }\end{array}$ & $\begin{array}{l}\text { Difference } \\
\text { (\%) }\end{array}$ \\
\hline W14X82 & 284.1 & 286.2 & 0.73 \\
W14x90 & 659.6 & 662.5 & 0.44 \\
W14x120 & 893.4 & 896.0 & 0.29 \\
\hline
\end{tabular}

Figures 2 through 4 illustrate the results summarized in columns four and five of Table 4 . These figures visually demonstrate the close agreement between the ABAQUS post-buckling estimates for compressive strength and the values calculated using the proposed $\mathrm{F}_{\mathrm{e}(\text { buckle) }}$ method. The nominal compressive strength calculated using AISC equations for the non-corroded cross-section are also included in Figures 2 through 4 for comparison.

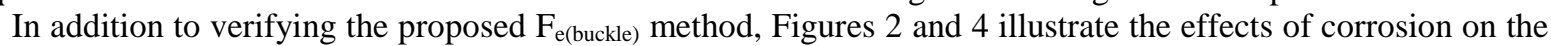
expected strength of a cross-section. A predictive method for capturing this reduction is the ultimate focus of the present work. The inherently non-linear nature of compressive strength reduction as a function of cross-section loss is apparent. Using the $\mathrm{P}_{\mathrm{n}(\text { post }}$ results for a basis of comparison, the W14x120 loses 33\% of capacity up to the point of $50 \%$ cross-sectional reduction, but over $81 \%$ of capacity is lost at $75 \%$.

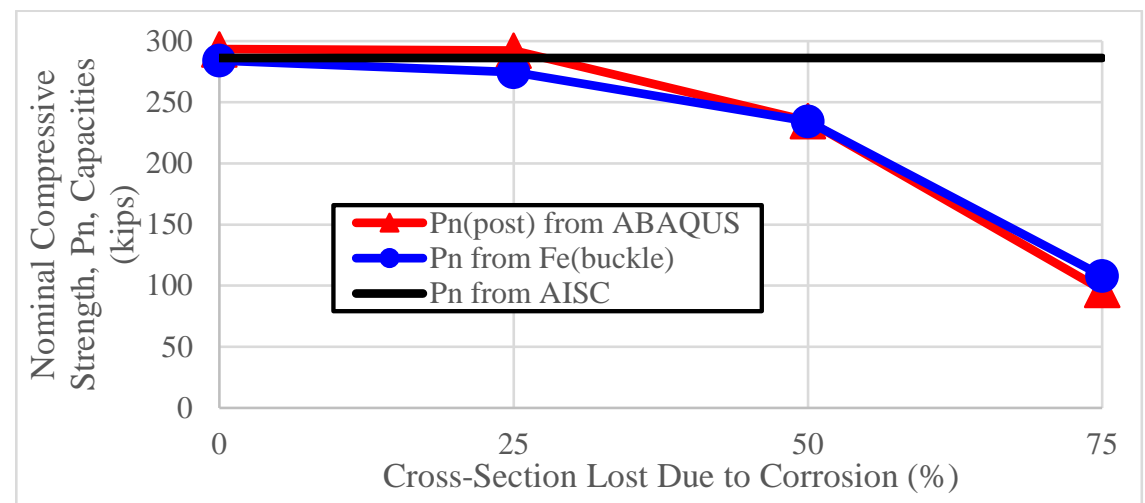

Figure 2. Comparison of nominal compressive strength values for both finite element methods and current AISC design equations for all W14x82 models.

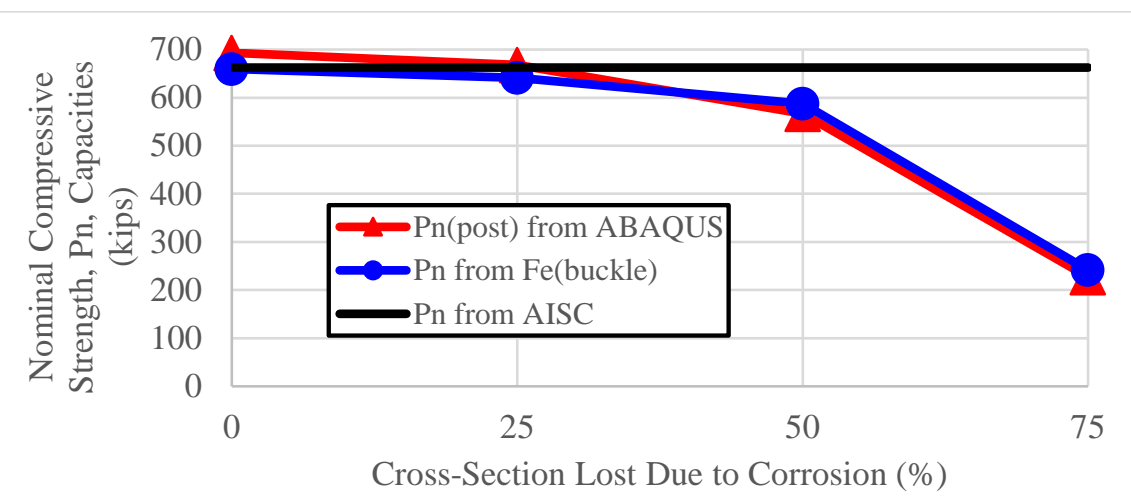

Figure 3. Comparison of nominal compressive strength values for both finite element methods and current AISC design equations for all W14x90 models. 


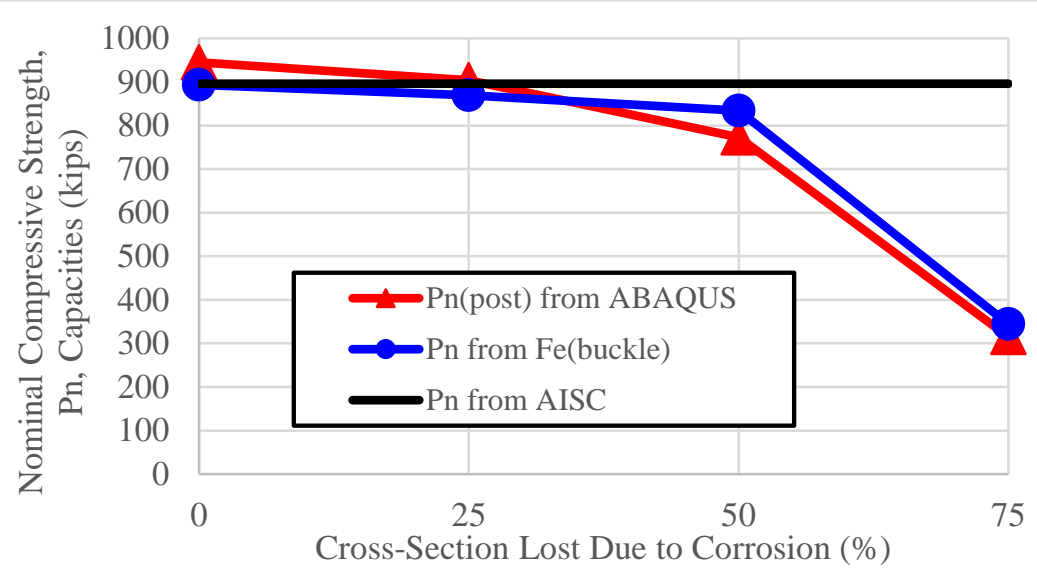

Figure 4. Comparison of nominal compressive strength values for both finite element methods and current AISC design equations for all W14x120 models.

Table 5 summarizes results for all twelve models considered in this study. These results include the critical buckling load obtained from the ABAQUS buckling analysis, the post-buckling compressive strength obtained from the ABAQUS Riks analysis, and the nominal compressive strength estimated using Equations (3), (4), and (5). Results for the geometries with $0 \%$ cross-section loss have already been presented in Tables 2 through 4 but are included to illustrate the effects of corrosion on the cross-section. For all geometries considered in this study, results for compressive strength obtained from post-buckling analysis and the proposed $\mathrm{F}_{\mathrm{e}(\text { buckle) }}$ procedure are within $11 \%$ of each other, with the largest difference occurring at the points of greatest cross-sectional loss (75\%). Since the proposed $\mathrm{F}_{\mathrm{e}(\mathrm{buckle})}$ procedure assumes a uniform cross-sectional loss and the ABAQUS model is corroded only in the splash zone, this variation is expected and appropriate. The proposed model does not yet address crosssectional variation within a compressive member, which is an important topic for further study.

Table 5. Comparison of ABAQUS and AISC results for all cross-sections

\begin{tabular}{llllll}
\hline $\begin{array}{l}\text { Model } \\
\text { Geometry }\end{array}$ & $\begin{array}{l}\text { Cross-Section } \\
\text { Loss } \\
\text { (\%) }\end{array}$ & $\begin{array}{l}\mathbf{P}_{\text {cr(buckle) from }} \\
\text { ABAQUS } \\
\text { (kips) }\end{array}$ & $\begin{array}{l}\mathbf{P}_{\mathbf{n}(\mathbf{p o s t}) \text { from }} \\
\text { ABAQUS } \\
\text { (kips) }\end{array}$ & $\begin{array}{l}\mathbf{P}_{\mathbf{n}} \text { from AISC } \\
\text { using Fe(buckle) } \\
\text { (kips) }\end{array}$ & $\begin{array}{l}\text { Difference } \\
\text { (\%) }\end{array}$ \\
\hline W14x82 & 0 & 324 & 293.5 & 284.1 & 3.31 \\
& 25 & 313 & 292.3 & 274.5 & 6.51 \\
& 50 & 267 & 234.7 & 234.3 & 0.18 \\
& 75 & 123 & 96.6 & 108.1 & 10.7 \\
\hline W14x90 & 0 & 795 & 693.2 & 659.6 & 5.11 \\
& 25 & 764 & 667.7 & 641.2 & 4.14 \\
& 50 & 682 & 566.7 & 587.6 & 6.02 \\
\hline W14x120 & 0 & 326 & 227.2 & 241.8 & 5.78 \\
& 25 & 1085 & 945.0 & 893.4 & 3.94 \\
& 50 & 1044 & 904.1 & 869.8 & 7.38 \\
\hline
\end{tabular}

\section{Recommendations and Conclusions}

Preliminary conclusions from the results presented in this work indicate that non-linear post-buckling analyses conducted in ABAQUS are in close (less than 6\% difference) agreement with AISC equation models for the noncorroded cross-sections. Moreover, it is clear that there is a sharp, nonlinear reduction in nominal compressive capacity with increasing cross-section losses due to corrosion in the splash zone.

The $\mathrm{F}_{\mathrm{e} \text { (buckle) }}$ method presented in this work would permit practicing engineers to calculate an estimate of nominal moment capacity based on a linear buckling analysis of a corroded cross-section. As linear finite element analyses are faster to implement and require fewer assumptions about material and geometric behavior than nonlinear models, the ability to estimate the effects of corrosion on residual compressive capacity with single linear model is of significant value. Results presented in this work show close agreement (within 11\%) between nonlinear post-buckling estimates of nominal compressive strength and those calculated using the $\mathrm{F}_{\mathrm{e}(\mathrm{buckle})}$ method.

In order to implement the results of a linear buckling analysis, the resulting critical buckling load, $\mathrm{P}_{\text {cr(buckle), }}$ 


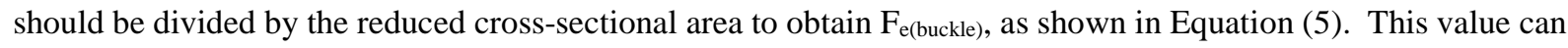
then be directly substituted for $\mathrm{F}_{\mathrm{e}}$ in the existing equations of AISC's Ch. E3.

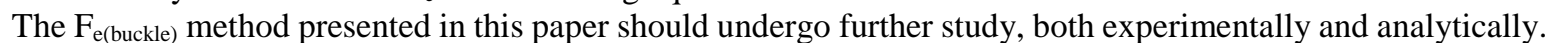
Variables to consider include different cross-sectional sizes and shapes, boundary conditions, and material properties. In additional to verifying the applicability of the $\mathrm{F}_{\mathrm{e}(\mathrm{buckle})}$ method over a larger population of data, this research may lead to more analytical methods for predicting the residual compressive capacity of a member as a function of corrosion loss. Such models will significantly improve engineers' abilities to estimate the effects of observed corrosion in existing structures.

\section{References}

[1] AISC. Steel construction manual, 15th Ed. American Institute of Steel Construction; 2017.

[2] Davis JR. Corrosion: Understanding the basics. ASM International; 2000.

[3] Zhao J, Xia L, Sehgal A, Lu D, McCreery RL, Frankel GS. Effects of chromate and chromate conversion coatings on corrosion of aluminum alloy 2024-T3. Surface and Coatings Technology. 2001;140(1):51-57.

[4] Wall H, Wadsö L. Corrosion rate measurements in steel sheet pile walls in a marine environment. Marine Structures. 2013;33:21-32.

[5] Cwalina B. Biodeterioration of concrete, brick and other mineral-based building materials. Understanding Biocorrosion. 2014:281-312.

[6] National Cooperative Highway Research Program. Guidelines for evaluating corrosion effects in existing steel bridges. Transportation Research Board National Research Council; 1990.

[7] Avcar M. Elastic buckling of steel columns under axial compression. American Journal of Civil Engineering. 2014;2(3):102-108.

[8] Narayana YV, Gunda JB, Reddy PR, Markandeya R. Nonlinear buckling and post-buckling analysis of imperfect cylindrical shells subjected to axial compressive load. Journal of Structural Engineering. 2015; 42 (2), 78-85.

[9] Zhang H, Ha L, Li Q, Beer M. Imprecise probability analysis of steel structures subject to atmospheric corrosion. Structural Safety. 2017;67:62-69.

[10] Bailey B, Deopurkar P, Samudrala LS, Upputuri LR. Elastic buckling capacities of piles subject to partial section loss. In: Proceedings of 2011 Conference on Coastal Engineering Practice. ASCE; 2011. p. 868-877.

[11] Abaqus analysis user's guide. Dassault Systems. 2016.

(C) 2019 by the author(s). This work is licensed under a Creative Commons Attribution 4.0 International License (http://creativecommons.org/licenses/by/4.0/). Authors retain copyright of their work, with first publication rights granted to Tech Reviews Ltd. 